\title{
Postoperative Pain After Cesarean Section at University of Gondar Comprehensive Specialized Hospital, Gondar, Northwest Ethiopia, 2019; a Cross- sectional Follow-Up Study
}

Yophtahe Woldegerima ( $\square$ yophtii@gmail.com )

University Of Gondar

Geta Demelash

Debre Markos University

Amare Hailekiros

University Of Gondar

Wubie Birlie

University Of Gondar

\section{Research Article}

Keywords: Pain, Post-cesarean section Pain, Postoperative Pain, Cesarean Section, Obstetric Anesthesia, Analgesia

Posted Date: November 25th, 2020

DOI: https://doi.org/10.21203/rs.3.rs-110955/v1

License: (9) This work is licensed under a Creative Commons Attribution 4.0 International License.

Read Full License 


\section{Abstract}

\section{Background}

Cesarean section is one of the most common obstetric procedures worldwide. Following this, parturients experience moderate to severe pain in the acute postoperative period. Therefore, in resource-limited settings, for full utilization of basic analgesic modalities and to take appropriates interventions, it is vital to know about the magnitude of the problem and its factors.

Objective

To assess the prevalence and factors associated with postoperative pain after cesarean section at the University of Gondar Comprehensive Specialized Hospital (UoGCSH), Northwest Ethiopia, 2019.

Methods

A hospital-based prospective follow-up study was conducted among parturients who undergo cesarean section in the University of Gondar Comprehensive Specialized Hospital, from mid-February to April 20, 2019 , after approval of the ethical review committee. Consecutively, a total of 290 parturients were included with a response rate of $97 \%$. To measure pain severity numerical rating scale was used. Data was entered into Epi-data version 4.2 and analyzed by SPSS version 20 (IBM Corporate). The association between independent factors and the outcome variable was determined at $95 \% \mathrm{Cl}$ with the chi-squared test, bivariate, and multivariate logistic regression. Hosmer-Lemeshow test was used to assess the goodness of fit. Variables with a p-value of $<0.05$ were considered significant.

Results

In this study, the incidence of moderate to severe post-operative pain after cesarean section was $85.5 \%$ (95\% Cl: 81.4\%, 89.0\%) within the first 24 postoperative hours. On the multi-variable analysis, preoperative anxiety (AOR: 2.3, 95\% Cl: 1.1, 4.9), history of previous cesarean section (AOR: 2.3, 95\% Cl: 1.1, 5.0), Pfannenstiel incision (AOR: $3.2,95 \% \mathrm{Cl}: 1.3,8.0$ ) and absence of regional analgesia (AOR: $3.7,95 \% \mathrm{Cl}$ : $1.7,7.9)$ were significantly associated with moderate to severe postoperative pain after cesarean section.

\section{Conclusions}

In this study, a large proportion of parturients had experienced moderate to severe post-cesarean pain in the first 24 postoperative hours. Preoperative anxiety, history of previous cesarean section, Pfannenstiel incision, and parturients with no regional analgesia were significantly associated with post-cesarean pain. Pain severity needs to be assessed and documented by using pain-rating scales and there should be an interdisciplinary approach to provide adequate pain management in our hospital.

\section{Background}


Cesarean section (CS) is one of the commonest obstetric procedure in the world and in Ethiopia as well $[1,2]$. Following this procedure, pain is the commonest and anticipated problem in the postoperative period [3]. Pain is a sensory and emotional experience which is influenced by physiologic, sensory, affective, cognitive, sociocultural and behavioral factors [4]. Surgical tissue damage increases peripheral and central sensitization which results in moderate to severe pain after CS [5-8], which leads to patient discomfort, decreased level of satisfaction and delayed recovery. Postoperative pain also can results in unwanted consequences, such as poor wound healing, prolonged hospital stay, poor quality-of-life, increased risk of morbidity, prolonged duration of opioid use and chronic pain. All of these have cost implications $[5,6,9]$. Especially in parturients who delivered with CS; if postoperative pain is inadequately treated, it may interfere with ambulation, breastfeeding, and other maternal care of the newborn. Having a baby is considered as a pleasant event, but it can be traumatic if the mother is in pain at the postoperative period [10]. Therefore, adequate pain relief after CS by using a safe and effective analgesic agent with different combinations, is a universal concern since pain relief is one of the basic human right [11].

Even though, there is no current "gold standard" post-cesarean pain management, there are many options of treatment modalities; of those, the most popular pain management modalities are; systemic and intrathecal administration of opioids, patient-controlled analgesia, intra-muscular injection of nonsteroidal anti-inflammatory drugs and regional nerve blocks. Generally, these pain management modalities combined as part of multimodal analgesia, which results in additive or synergistic analgesia with lowered side effects $[7,8,12,13]$.

Despite such advances in pain management, parturients experience moderate to severe pain in the acute postoperative period, which is recognized as a major clinical problem that affects mothers and their newborns [10]. As previous studies reported, parturients after CS had $78.4 \%$ to $92 \%$ chance of experiencing moderate to severe pain. But very little is known about the magnitude of post-cesarean section pain and factors associated with post-cesarean section pain in the developing countries, especially in the sub-Saharan Africa. The developing world has multiple dimensions of challenges to assess and provide adequate pain management services. These challenges are commonly associated with scarcity of well-trained clinician, materials, drugs and facilities. [5-8]. The objectives of this study was to assess the incidence of postoperative pain after CS and identify the factors associated with postoperative pain after CS at University of Gondar Comprehensive Specialized Hospital, Gondar, Northwest Ethiopia, 2019.

\section{Methods}

A Hospital-based prospective follow up study was conducted from mid, February to April 20, 2019, in University of Gondar Comprehensive Specialized Hospital (UoGCSH). The Hospital is located in Gondar town, Northwest Ethiopia. Cesarean section (CS) is the commonly performed surgical operation with an average of 120 - 160 operation per month in two functional operation theatres that are dedicated for CS only. 
The source population was all parturients who gave birth by CS under anesthesia and study population was all parturients who gave birth by CS under anesthesia at UoGCSH during the study period were the study. All volunteer adult (18+) parturients that underwent CS under both spinal and general anesthesia were included in this study. Parturients who had pre-existing cognitive dysfunction and those who had an ongoing treatment for chronic pain were excluded.

The dependent variable was postoperative pain after CS which was measured with numerical rating scale (NRS). The independent variables were socio-demographic factors (age, body mass index, religion, educational status, marital status and ethnicity), clinical factors (preoperative visit by anesthetists, preoperative anxiety, history of previous CS, preoperative use of analgesics, ASA status, and parity), intraoperative factors (type of surgery, type of incision, length of incision, type of anesthesia, the status of the newborn, surgical time, anesthesia time, regional nerve blocks and intraoperative analgesics) and postoperative factors (types of analgesics given at the postoperative period).

Numerical rating scale with 11 points (NRS-11) is a valid and reliable pain assessment tool in which the number assigned from $0-10$ to represent the severity of pain: $0=$ no pain, $1-3=\operatorname{mild}$ pain, $4-6=$ moderate pain, $7-10$ = severe pain [14]. In this study, NRS-11 was preferred to use due to its simplicity to understand by the parturients. Tolerable pain threshold is defined as a treatment threshold of pain score with a cut of point of NRS-11 $\geq 4$, which was considered to identify patients with pain of moderate to severe intensity $[15,16]$. Full return of consciousness is defined as a state of consciousness of an individual when he/she is awake or easily arousable and aware of his surroundings and identity after general anesthesia [17]. Spinal anesthesia wear-off is defined as a period of time the spinal anesthetic ends up and patients will gradually start to be able to feel and move their legs and may experience tingling or pins and needles in their legs [18].

To determine sample size, single population proportion formula was used. A study done in South Africa reported that the incidence of moderate to severe pain during the first 24 postoperative hours and in the immediate postoperative period after cesarean section was (87\%) [19]. By assuming 95\% of confidence interval with $4 \%$ margin of error, the sample size for the study was calculated as so based on this data sample size of this study was calculated by using a single population aproportion formula as:

$$
n=\left(z \frac{\alpha}{2}\right)^{2} x p(1-p) / \varepsilon^{2}
$$

We have $\mathrm{p}=0.87, \varepsilon=0.04, \mathrm{Za} / 2$ at $95 \% \mathrm{Cl}=1.96$

\section{$\mathrm{n}=(1.96)^{2}(0.87 \times 0.13) /(0.04)^{2}$}

$\mathbf{n}=\mathbf{2 7 1 . 6} \approx \mathbf{2 7 2}$, then when we added $10 \%$ of the non-response rate, the sample size was $\mathbf{n}=\mathbf{2 9 9}$.

All eligible consecutive parturients who underwent cesarean section were included in the study till the calculated sample size reached. 
Data was collected by using a pre-tested structured questionnaire. The questionnaire was primarily prepared in English language and translated to Amharic language. Training for data collectors and supervisors was provided by the principal investigator. A pilot was conducted on 30 (10\%) patients who were not included in the main study. Then necessary corrections were made accordingly to the questionnaire for the main study. The data collectors and supervisors were closely mentored by the principal investigator throughout the study period. Study participants were provided with adequate information regarding assessment tool (NRS-11). The data collectors took informed consent; reviewed the charts and document pain severity at rest and on movement by using NRS-11 at 2, 12, 24 postoperative hours. The type, doses and time of administered analgesics were also documented. The collected data was checked for the completeness and clarity

After completion of data collection, the variables were coded and cleaned. The data was entered into the Epi-data software (version 4.2) for cleaning for errors and was analyzed by SPSS version 20 (IBM Corporate). The normality of the data was tested by using Shapiro-Wilk normality test. Descriptive statistic was done and presented with frequency, percentage, mean, standard deviation, median and interquartile range (IQR). The relationships of nominal data with postoperative pain were analyzed by using cross-tabulations. Hosmer and Lemeshow test was used to assess the goodness of fit. The associations between the independent variables and outcome variable were determined at $95 \%$ confidence interval with chi-squared test, bivariate and multivariate binary logistic regression. The cut-point of statistical significance was $\mathrm{P}<0.2$ for bivariate and 0.05 for multivariate regression. Crude and adjusted Odds Ratio were used to see the strength of the association for bivariate and multivariate logistic regression respectively.

\section{Results}

A total of 290 parturients who deliver with cesarean section were involved in this study with a $97 \%$ response rate. Nine patients were excluded from the analysis due to incomplete data. The ages of the majority of parturients $219(75.5 \%)$ fall between 18 to 34 years. The median age (IQR) $28(25-30.3)$ years. The median (IQR) of BMI of the parturients was $22.6(20.6-24.6) \mathrm{Kg} / \mathrm{m}^{2}$ respectively. The majority 206 (71\%). had a normal BMI between $18.5-24.5$ [Table 1].

The majority of parturients 258 (89\%) were ASA II while only $32(11 \%)$ were ASA III and above. Most of the parturients had not given analgesics at the preoperative period 264 (91\%), while few of them had received as preemptive analgesia or for the treatment of their pain $26(9 \%)$ [Table 2]. A Large proportion of parturients 269 (92.8\%) had undergone CS under spinal anesthesia, while only about 21 (7.2\%) of parturients were with general anesthesia. About 190 (65.5\%) of parturients were presented for emergency CS and the rest 100 (34.5\%) were scheduled for elective CS [Table 3].

The NRS-11 score at the $2^{\text {nd }}$ postoperative hr shows that $71(24.5 \%)$ of parturients experienced none to mild pain, while, about 219 (75.5\%) of parturients reported to have moderate to severe pain. At the $12^{\text {th }} \mathrm{hr}$ more parturients $232(80.0 \%)$ had moderate to severe pain compared to the $2^{\text {nd }}$ hr and only $58(20.0 \%)$ 
had scores for no to mild pain. At the $24^{\text {th }} \mathrm{hr}$, about $120(41.4 \%)$ had experienced no to mild pain while $170(58.6 \%)$ experience moderate to severe pain. The overall incidence of moderate to severe postoperative pain after CS was $85.5 \%$ (95\% Cl: 81.4\%, 89.0\%) in the first 24 postoperative hours [Figure 1].

About 152 (52.4\%) of the parturients did not received any analgesics at the $2^{\text {nd }} \mathrm{hr}$. Out of those who took analgesics at this time $(138(47.4 \%))$, the majority $101(73.2 \%)$ had received diclofenac. The number of parturients that received analgesics was increased at the $12^{\text {th }} \mathrm{hr}$. About $224(77.2 \%)$ had received certain types of systemic analgesics. Diclofenac and tramadol were the leading analgesics administered to treat pain. At the $24^{\text {th }} \mathrm{hr}$, about 107 (36.9\%) of parturients did not obtain any analgesics. [Figure 2].

The most commonly practiced regional analgesic options for postoperative pain relief after CS in the hospital were epidural analgesia, abdominal field blocks such as TAP block and IL/IH nerve blocks and para-incisional wound infiltration. However, these regional analgesic were done only in about 66 (22.8\%) of parturients, while the remaining 224 (77.2\%) of parturients had not received regional analgesia. Among those regional analgesics, the most frequent 35 (53.0\%) was TAP block [Figure 3].

On the bivariate binary logistic regression analysis; BMI, educational status, preoperative anxiety, history of previous cesarean section, type of incision, length of incision, administration of regional nerve blocks and systemic analgesics given at $12^{\text {th }}$ hr were found significantly associated with postoperative pain $(p<$ 0.2). However, on the multivariate binary logistic regression analysis; preoperative anxiety, history of previous cesarean section, type of incision and administration of regional nerve blocks were found significantly associated with postoperative pain after cesarean section $(p<0.05)$. [Table 4].

Parturients who had preoperative anxiety were 2.3 times more likely to had moderate to severe postoperative pain than those who were not anxious (AOR: 2.3, 95\% Cl: 1.1, 4.9). Similarly, the odds of having moderate to severe postoperative pain were 2.31 times (AOR: $2.3,95 \% \mathrm{Cl}$ : 1.1, 5.0) higher among parturients who had history of previous cesarean section than those parturients who not. The study also revealed that the likelihood of having moderate to severe post-operative pain after CS was 3.2 times (AOR: $3.2,95 \% \mathrm{Cl}: 1.3,8.0$ ) higher during transverse incision compared to midline incision. Parturients who had not received regional analgesia and para-incisional wound infiltration as part of multimodal analgesia were 3.7 times (AOR: $3.7,95 \% \mathrm{Cl}: 1.7,7.8)$ more likely to have moderate to severe postoperative pain [Table 4].

\section{Discussion}

The current study was designed to measure the incidence of postoperative pain after CS and identify factors associated with it in the first 24 postoperative hours. We found that the overall incidence of moderate to severe postoperative pain in the first 24 postoperative hours was $85.5 \%$ ( $95 \% \mathrm{Cl}: 81.4 \%$, $89.0 \%$ ). Moderate to severe pain was reported in $75.5 \%$ of parturients at the $2^{\text {nd }} \mathrm{hr}, 80 \%$ at the $12^{\text {th }} \mathrm{hr}$ and $58.6 \%$ at the $24^{\text {th }} \mathrm{hr}$. This shows that there was inadequate treatment of pain at the postoperative period 
after cesarean section. Pain is the prevalent problem and undermanaged in patients subjected to different types of surgical operations including CS $[19,20]$. Postoperative pain after CS is still poorly controlled and results in adverse outcomes in the wellbeing of both the mother and her newborn. Several studies have revealed that there is a high incidence (78-93\%) of moderate to severe postoperative pain after CS [19, $21-25]$.

The incidence of moderate to severe postoperative pain in surgical patients other than CS was $88.2 \%$ in Jimma, Southwest Ethiopia and $57 \%$ at $2^{\text {nd }} \mathrm{hr}$ and $78 \%$ at $12^{\text {th }} \mathrm{hr}$ in Gondar, Northwest Ethiopia $[19,26]$. This results exposed inadequate treatment of pain of surgical patients in the country. A prospective cohort study done in the United States of America shown that the incidence of severe acute pain within the first 36 postoperative hours was $10.9 \%$ [24], which is much lower compared to our findings. The variations could be explained by larger and multicenter sample size and better practice on pain management in the developed United States of America. Another prospective survey in Uganda reported that the incidence of severe acute pain after CS at three time-points at Zero, $6^{\text {th }}$ and $24^{\text {th }} \mathrm{hr}$ since surgery was $33 \%, 39 \%$ and $29 \%$ respectively [25]. In-contrast, the incidence of postoperative pain was much higher in our study at all time-points $\left(2^{\text {nd }}, 12^{\text {th }}\right.$, and $\left.24^{\text {th }} \mathrm{hr}\right)$. The discrepancy could be due to the difference of time-points of assessment. In the Ugandan study clients were assessed for pain as soon as arrived at the recovery area (Zero hour); and at this time-point spinal anesthesia might not wear off. Furthermore, the use of different pain scales could be another reason for the disparities since they used visual analogue scale while we used NRS-11. The most commonly prescribed analgesic for postoperative pain management was intramuscular diclofenac followed by tramadol. This finding is similar with the Ugandan study [25]. This could show the underuse of multiple classes of analgesics to manage postoperative pain in low-income countries. It was 3.7 times more likely to develop moderate to severe postoperative pain if regional analgesics (neuraxial, peripheral or para-incisional wound infiltration) were not administered as parts of multimodal analgesia. Multiple studies have supported that para-incisional wound infiltration and abdominal nerve blocks after both spinal and general anesthesia can alleviate pain after CS and reduce opioid consumption [27 - 29].

Preoperative anxiety was found to be one of the factors associated with pain after CS. Parturients who had anxiety at the preoperative period were 2.3 times more likely to complain for moderate to severe postoperative pain than those who were not anxious. Comparably, a study done in Brazil has revealed that the likelihood of having moderate to severe postoperative pain was 1.6 times in mothers who were anxious at the preoperative period [22]. In addition, a previous study in our hospital showed that about $51.7 \%$ of patients had preoperative anxiety due to a fear of postoperative pain [30]. Anxiety and fear of pain can predict postoperative pain after CS [31].

The type of incisions significantly affected the patterns of postoperative pain after CS. The Pfannenstiel incisions were more likely to cause moderate to severe pain (AOR: $3.2,95 \% \mathrm{Cl}: 1.3,8.0$ ) than the midline incisions. A study done in the United States of America shown no significant difference in postoperative pain when CS performed either with midline or pfannenstiel incisions [32], Despite these, a Danish study has concluded that midline incision is associated with having higher postoperative pain [33]. An RCT in 
Thailand found out that pain of the vertical incisions was higher than Pfannenstiel incisions at the $3^{\text {rd }}$, $12^{\text {th }}$ and $24^{\text {th }}$ postoperative hours in primary CS. However, in repeated CS, pain of Pfannenstiel incisions

was higher at the $6^{\text {th }}$ and $12^{\text {th }}$ postoperative hours [34]. The possible reasons to this dissimilarities might be explained by the length of incisions. The recommended optimal length of incision for CS is $<10 \mathrm{~cm}$ [35]. Compared to others, larger proportions of parturients (49\%) had incision length of $\geq 10 \mathrm{~cm}$. This might have increased the likelihood of injury to the nerves of the abdominal wall and increased the incidence and intensity of postoperative pain. Pfannenstiel is the most performed type of incision in 246 (84.8\%) of the parturient. It was considered to offers adequate pelvic exposure, excellent postoperative strength, reduced risk of disruption and incisional hernia, decreased risk of hypertrophic scar and good cosmetic results [33].

This study has proved the significant association between previous CS and postoperative pain. Parturients who had the experience of previous CS were more likely to have moderate to severe pain (AOR: 2.3, 95\% Cl: 1.1 - 5). The association can be explained by increased risks of longer operating time and hospital stay, uterine dehiscence, bleeding, postoperative infection and adhesion [34, 36, 37].

The strengths of the study are that it is the first in its type at the setup and the country at large. So it can be used as a cornerstone for the future studies in the field. It has measured the magnitude of the problem and identified factors that affected the problem. We believe that the results of the study can be used as a waking alarm for the stake-holders in the maternal care and help them to take appropriate actions to tackle the problem. The limitation of the study is its inability to show cause and effect relations since it is done with a cross-sectional design.

\section{Conclusion And Recommendations}

The overall incidence of moderate to severe postoperative pain in the first 24 postoperative hours was very high and it occurred in $85.5 \%$ of parturients delivered by CS. This shows poor pain management in the recovery rooms and maternity wards. Parturients who had preoperative anxiety, history of previous CS, pfannenstiel incisions and those who did not received regional analgesia had suffered from moderate to severe postoperative pain after CS. According to our findings, we recommended that the hospital should insure adequate and appropriate drugs and materials for pain management in the recovery rooms and maternity wards, provide regular training on pain management and assessment for clinicians who practice in the maternity care, and introduce appropriate modalities that can help relieving preoperative anxiety. Clinicians should provide special attention for parturients who has preoperative anxiety, history of previous CS and long Pfannenstiel incisions. They also should facilitate for the adequate access and provision of regional analgesia in the postoperative period.

\section{Abbreviations}

AOR Adjusted Odds Ratio 
ASA American Society of Anesthesiologists

BMI Body Mass Index

CS Cesarean Section

IL/IH Ilioinguinal /lliohypogastric

NRS Numerical Rating Scale

TAP Transvers Abdominus Plane

UOGCSH University of Gondar Comprehensive Specialized Hospital

\section{Declarations}

\section{Acknowledgements}

None

\section{Funding}

College of Medicine and Health Sciences, University of Gondar and College of Medicine and Health Science, Debre-Markos University

\section{Availability of data and materials}

Data and materials used in this study are available and can be presented by the corresponding author upon reasonable requests.

\section{Authors' contributions}

GD, YBW conceptualized the study and objectives. GD developed the proposal. YBW, AGH, and WBC criticized the proposal. All the authors had participated in the data and statistical analyses. YBW led the manuscript preparation. All the authors read and approved the final manuscript.

\section{Ethics approval and consent to participate}

Ethical clearance to conduct the research was obtained from Ethical Review Board of School of Medicine, College of Medicine and Health Sciences, University of Gondar. Written informed consent form using Amharic and English languages was presented. Consent was taken from each study patients after brief explanation. Every participant was allowed to discontinue participation if did not want to finish it. Also the participants were assured that their treatment and other benefits they can gain from the hospital will not be interrupted due to their withdrawal. Confidentiality was ensured by removing identifiers and locking the questionnaires after data collection in a secured area. Additionally, when patients found experiencing 
significant anxiety in the preoperative period, the data collectors had reported for the corresponding care giver (Anesthetist, Surgeon or Nurse) to provide pain management.

\section{Consent for publication}

Not applicable; this article does not include any personal or clinical details of any participant.

\section{Competing interests}

The authors declared that they have no competing interests.

\section{References}

1. Yisma E, et al. Cesarean section in Ethiopia: prevalence and sociodemographic characteristics. The Journal of Maternal-Fetal \& Neonatal Medicine. 2017:1-6.

2. Hehir MP, et al. Cesarean delivery in the United States 2005 through 2014: a population-based analysis using the Robson 10-Group Classification System. American Journal of Obstetrics \& Gynecology. 2018.

3. Caumo W, et al. Preoperative predictors of moderate to intense acute postoperative pain in patients undergoing abdominal surgery. Acta Anaesthesiologica Scandinavica. 2002;46(10):1265-71.

4. Loeser JD, et al. Pain: an overview. Lancet (London, England). 1999;353(9164):1607-9.

5. Wang $L$, et al. Incidence and risk factors for chronic pain after elective caesarean delivery under spinal anaesthesia in a Chinese cohort: a prospective study. International journal of obstetric anesthesia. 2018;34:21-7.

6. Sinatra R. Causes and Consequences of Inadequate Management of Acute Pain. Pain Medicine. 2010;11(12):1859-71.

7. Recker DC, et al. Postsurgical pain syndromes: Chronic pain after hysterectomy and cesarean section. Techniques in Regional Anesthesia and Pain Management. 2011;15(3):133-9.

8. Gamez BH, Habib AS. Predicting severity of acute pain after cesarean delivery: a narrative review. Anesthesia \& Analgesia. 2018;126(5):1606-14.

9. Niklasson B, et al. Risk factors for persistent pain and its influence on maternal wellbeing after cesarean section. Acta obstetricia et gynecologica Scandinavica. 2015;94(6):622-8.

10. Pereira TRC, et al. Implications of pain in functional activities in immediate postpartum period according to the mode of delivery and parity: an observational study. Brazilian journal of physical therapy. 2017;21(1):37-43.

11. Pan PH. Post cesarean delivery pain management: multimodal approach. International journal of obstetric anesthesia. 2006;15(3):185-8.

12. Thais Orrico de Brito Cançado ea. <Chronic Pain after Cesarean Section. Influence of.pdf >. Rev Bras Anestesiol. 2012. 
13. Bamigboye AA, et al. Local anaesthetic wound infiltration and abdominal nerves block during caesarean section for postoperative pain relief. Cochrane Database of Systematic Reviews. 2009(3).

14. Breivik H, et al. Assessment of pain. BJA: British Journal of Anaesthesia. 2008;101(1):17-24.

15. Gerbershagen HJ, Rothaug J, Kalkman C, Meissner W. Determination of moderate-to-severe postoperative pain on the numeric rating scale: a cut-off point analysis applying four different methods. British journal of anaesthesia. 2011;107(4):619-26.

16. Birnie KA, et al. When does pain matter? Acknowledging the subjectivity of clinical significance. Pain. 2012;153(12):2311-4.

17. Misal US, et al. Delayed recovery from anesthesia: A postgraduate educational review. Anesthesia, essays and researches. 2016;10(2):164-72.

18. Imarengiaye $\mathrm{CO}$, et al. Spinal Anesthesia Functional Balance Is Impaired after Clinical Recovery. The Journal of the American Society of Anesthesiologists. 2003;98(2):511-5.

19. Murray AA, et al. Acute postoperative pain in 1231 patients at a developing country referral hospital: incidence and risk factors. Southern African Journal of Anaesthesia and Analgesia. 2015:1-6.

20. Admassu W, et al. Severity and risk factors of post-operative pain in university of gondar hospital, Northeast Ethiopia. Journal of Anesthesia \& Clinical Research. 2016;7(10):675.

21. Karlström A, et al. Postoperative pain after cesarean birth affects breastfeeding and infant care. Journal of Obstetric, Gynecologic \& Neonatal Nursing. 2007;36(5):430-40.

22. Borges NC, et al. Predictors for Moderate to Severe Acute Postoperative Pain after Cesarean Section. 2016;2016:5783817.

23. Borges NC, et al. Postoperative pain in women undergoing caesarean section. Enfermería Global. 2017;16(4):374-83.

24. Eisenach JC, et al. Severity of acute pain after childbirth, but not type of delivery, predicts persistent pain and postpartum depression. Pain. 2008;140(1):87-94.

25. Kintu $A$, et al. Postoperative pain after cesarean section: assessment and management in a tertiary hospital in a low-income country. BMC health services research. 2019;19(1):68.

26. Eshete MT, et al. Quality of postoperative pain management in Ethiopia: A prospective longitudinal study. 2019;14(5):e0215563.

27. Poudel $A$, et al. Postoperative analgesia with bilateral ilioinguinal and iliohypogastric nerve block in lower segment cesarean section. Journal of Society of Anesthesiologists of Nepal. 2017;4(2):81-6.

28. Bamigboye AA, et al. Caesarean section wound infiltration with local anaesthetic for postoperative pain relief-any benefit? South African medical journal. 2010;100(5).

29. Boztosun $A$, et al. Abdominal blockage of iliohypogastric and ilio-inguinal nerves for management of post-caesarean pain: A novel method. South African Journal of Obstetrics and Gynaecology. 2012;18(1):23-7.

30. Woldegerima Y. et al. Prevalence and factors associated with preoperative anxiety among elective surgical patients at University of Gondar Hospital. Gondar, Northwest Ethiopia, 2017. A cross- 
sectional study. International Journal of Surgery Open. 2017.

31. Carvalho B, et al. A Prospective Cohort Study Evaluating the Ability of Anticipated Pain, Perceived Analgesic Needs, and Psychological Traits to Predict Pain and Analgesic Usage following Cesarean Delivery. Anesthesiol Res Pract. 2016;2016:7948412.

32. Habib AS, et al. Comparison of postoperative pain outcomes after vertical or Pfannenstiel incision for major gynecologic surgery. Current medical research and opinion. 2009;25(6):1529-34.

33. Maaløe N, et al. Midline versus transverse incision for cesarean delivery in low-income countries. International Journal of Gynecology \& Obstetrics. 2014;125(1):1-2.

34. Suwannarurk K, et al. Post-Cesarean Pain Associated with Skin Incision: Vertical versus Pfannenstiel. JOURNAL OF THE MEDICAL ASSOCIATION OF THAILAND. 2017;100(6):162.

35. Gizzo S, et al et al. Caesarean section: could different transverse abdominal incision techniques influence postpartum pain and subsequent quality of life? A systematic review. PloS one. 2015;10(2):e0114190.

36. Biler A, et al. Is it safe to have multiple repeat cesarean sections? A high volume tertiary care center experience. Pakistan journal of medical sciences. 2017;33(5):1074-9.

37. Bakhshi T, et al. Maternal and neonatal outcomes of repeat cesarean delivery in women with a prior classical versus low transverse uterine incision. American journal of perinatology. 2010;27(10):791-6.

\section{Tables}

Table 1: Socio-demographic characteristics of the parturients who delivered with Cesarean Section at University of Gondar Comprehensive Specialized Hospital, Northwest Ethiopia; 2019, ( $N=290)$. 


\begin{tabular}{|c|c|c|}
\hline Variables & Frequency (n) & Percentage (\%) \\
\hline \multicolumn{3}{|l|}{ Age } \\
\hline $18-34$ & 219 & 75.5 \\
\hline$\geq 35$ & 71 & 24.5 \\
\hline \multicolumn{3}{|l|}{ BMI $\left(\mathrm{Kg} / \mathrm{m}^{2}\right)$} \\
\hline Underweight & 11 & 3.8 \\
\hline Normal & 194 & 66.9 \\
\hline Overweight & 56 & 19.3 \\
\hline Obese & 29 & 10.0 \\
\hline \multicolumn{3}{|l|}{ Marital Status } \\
\hline Unmarried & 11 & 3.8 \\
\hline Married & 269 & 92.8 \\
\hline Divorced & 10 & 3.4 \\
\hline \multicolumn{3}{|l|}{ Educational status } \\
\hline Illiterate & 41 & 14.2 \\
\hline Primary school & 56 & 19.3 \\
\hline Secondary school & 92 & 31.7 \\
\hline College and above & 101 & 34.8 \\
\hline
\end{tabular}

BMI: Body Mass Index

Table 2: Health status and clinical characteristics of parturients who delivered Cesarean Section at University of Gondar Comprehensive Specialized Hospital, Northwest Ethiopia; 2019, ( $N=290)$. 


\begin{tabular}{|lll|}
\hline Variables & Frequency (n) & Percentage (\%) \\
\hline ASA status & & \\
II & 258 & 89.0 \\
III and above & 32 & 11.0 \\
\hline $\begin{array}{l}\text { Preoperative anxiety } \\
\text { Yes }\end{array}$ & 151 & 52.1 \\
No & 139 & 47.9 \\
\hline $\begin{array}{l}\text { Preoperative analgesics } \\
\text { Yes }\end{array}$ & 26 & \\
No & 264 & 91.0 \\
\hline Parity & & \\
Nulliparous & 122 & 42.1 \\
Multiparous & 168 & 57.9 \\
\hline History of previous Cesarean Section & & \\
Yes & 196 & 67.6 \\
No & 94 & 32.4 \\
\hline
\end{tabular}

ASA: American Society of Anesthesiologists

Table 3: A cross-tabulation of the intraoperative factors with postoperative pain after Cesarean Section in University of Gondar Comprehensive Specialized Hospital, Northwest Ethiopia; 2019, ( $N=290)$. 


\begin{tabular}{|c|c|c|c|c|}
\hline \multirow[t]{2}{*}{ Variables } & \multirow[t]{2}{*}{ Frequency (n) } & \multirow[t]{2}{*}{ Percentage (\%) } & \multicolumn{2}{|c|}{ Overall postoperative pain in 24 hours } \\
\hline & & & None to mild & Moderate to sever \\
\hline \multicolumn{5}{|l|}{ Urgency of CS } \\
\hline Emergency & 190 & 65.5 & 28 & 162 \\
\hline Elective & 100 & 34.5 & 14 & 86 \\
\hline \multicolumn{5}{|l|}{ Type of incision } \\
\hline Midline & 44 & 15.2 & 11 & 33 \\
\hline Pfannenstiel & 246 & 84.8 & 31 & 215 \\
\hline \multicolumn{5}{|l|}{ Length of incision } \\
\hline$<10 \mathrm{~cm}$ & 148 & 51.0 & 26 & 122 \\
\hline$\geq 10 \mathrm{~cm}$ & 142 & 49.0 & 16 & 126 \\
\hline \multicolumn{5}{|l|}{ Type of anesthesia } \\
\hline General & 21 & 7.2 & 3 & 18 \\
\hline Spinal & 269 & 92.8 & 39 & 230 \\
\hline \multicolumn{5}{|l|}{ Surgical time } \\
\hline$<60$ minutes & 273 & 94.1 & 39 & 234 \\
\hline$\geq 60$ minutes & 17 & 5.9 & 3 & 14 \\
\hline \multicolumn{5}{|l|}{ Regional nerve blocks } \\
\hline Yes & 66 & 22.8 & 18 & 48 \\
\hline No & 224 & 77.2 & 24 & 200 \\
\hline
\end{tabular}

CS: Cesarean Section

Table 4: Bivariate and multivariate binary logistic regression: factors associated with postoperative pain after cesarean section at University of Gondar Comprehensive Specialized Hospital, Northwest Ethiopia; 2019, (X-tab and OR with 95\% $\mathrm{Cl})(\mathrm{N}=290)$. 


\begin{tabular}{|c|c|c|c|c|}
\hline \multirow[t]{2}{*}{ Variables } & \multicolumn{2}{|c|}{ Overall postoperative pain in 24 hours } & \multicolumn{2}{|c|}{ Odds Ratio (95\% Cl) } \\
\hline & $\begin{array}{l}\text { None to mild } \\
\mathrm{n}(\%)\end{array}$ & $\begin{array}{l}\text { Moderate to severe } \\
n(\%)\end{array}$ & Crude & Adjusted \\
\hline \multicolumn{5}{|l|}{$\begin{array}{l}\text { Preoperative } \\
\text { anxiety }\end{array}$} \\
\hline Yes & $15(9.9)$ & $136(90.1)$ & $\begin{array}{l}2.19(1.1, \\
4.3)\end{array}$ & $\begin{array}{l}2.3(1.1 \\
4.9)\end{array}$ \\
\hline No & $27(19.4)$ & $112(80.6)$ & 1】 & 1ه \\
\hline \multicolumn{5}{|l|}{$\operatorname{BMI}\left(\mathrm{Kg} / \mathrm{m}^{2}\right)$} \\
\hline$<30$ & $41(15.7)$ & $220(84.3)$ & 18 & 1 \\
\hline$\geq 30$ & $1(3.4)$ & $28(96.6)$ & $\begin{array}{l}5.2(1.1 \\
4.3)\end{array}$ & $\begin{array}{l}4.3(0.5 \\
34.4)\end{array}$ \\
\hline \multicolumn{5}{|l|}{$\begin{array}{l}\text { History of } \\
\text { previous CS }\end{array}$} \\
\hline \multirow{2}{*}{ Yes } & \multirow{2}{*}{$\begin{array}{l}24(12.2) \\
18(19.1)\end{array}$} & \multirow{2}{*}{$\begin{array}{l}172(87.8) \\
76(80.9)\end{array}$} & $\begin{array}{l}1.7(0.8 \\
3.3)\end{array}$ & $\begin{array}{l}2.3(1.1 \\
5.0)\end{array}$ \\
\hline & & & 1区 & 10 \\
\hline \multicolumn{5}{|l|}{ Type of incision } \\
\hline Pfannenstiel & $31(12.6)$ & $215(87.4)$ & $\begin{array}{l}2.3(1.1 \\
5.0)\end{array}$ & $\begin{array}{l}3.17(1.3, \\
8.0)\end{array}$ \\
\hline Midline & $11(25.0)$ & $33(75.0)$ & $1 \rrbracket$ & 10 \\
\hline \multicolumn{5}{|l|}{ Length of incision } \\
\hline$<10 \mathrm{~cm}$ & $26(17.6)$ & $122(82.4)$ & 1区 & 1 \\
\hline$\geq 10 \mathrm{~cm}$ & $16(11.3)$ & $126(88.7)$ & $\begin{array}{l}1.7(0.9 \\
3.3)\end{array}$ & $\begin{array}{l}1.5(0.7 \\
3.1)\end{array}$ \\
\hline \multicolumn{5}{|l|}{$\begin{array}{l}\text { Regional nerve } \\
\text { blocks }\end{array}$} \\
\hline & $18(27.3)$ & $48(72.7)$ & 18 & 1区 \\
\hline No & $24(10.7)$ & $200(89.3)$ & $\begin{array}{l}3.1(1.6 \\
6.2)\end{array}$ & $\begin{array}{l}3.7(1.7 \\
7.9)\end{array}$ \\
\hline
\end{tabular}

Q Significant from bivariate binary logistic regression analysis

Q Significant from multivariate binary logistic regression analysis

OR: Odds Ratios, Cl: Confidence Interval, BMI: Body Mass Index, CS: Cesarean Section

\section{Figures}




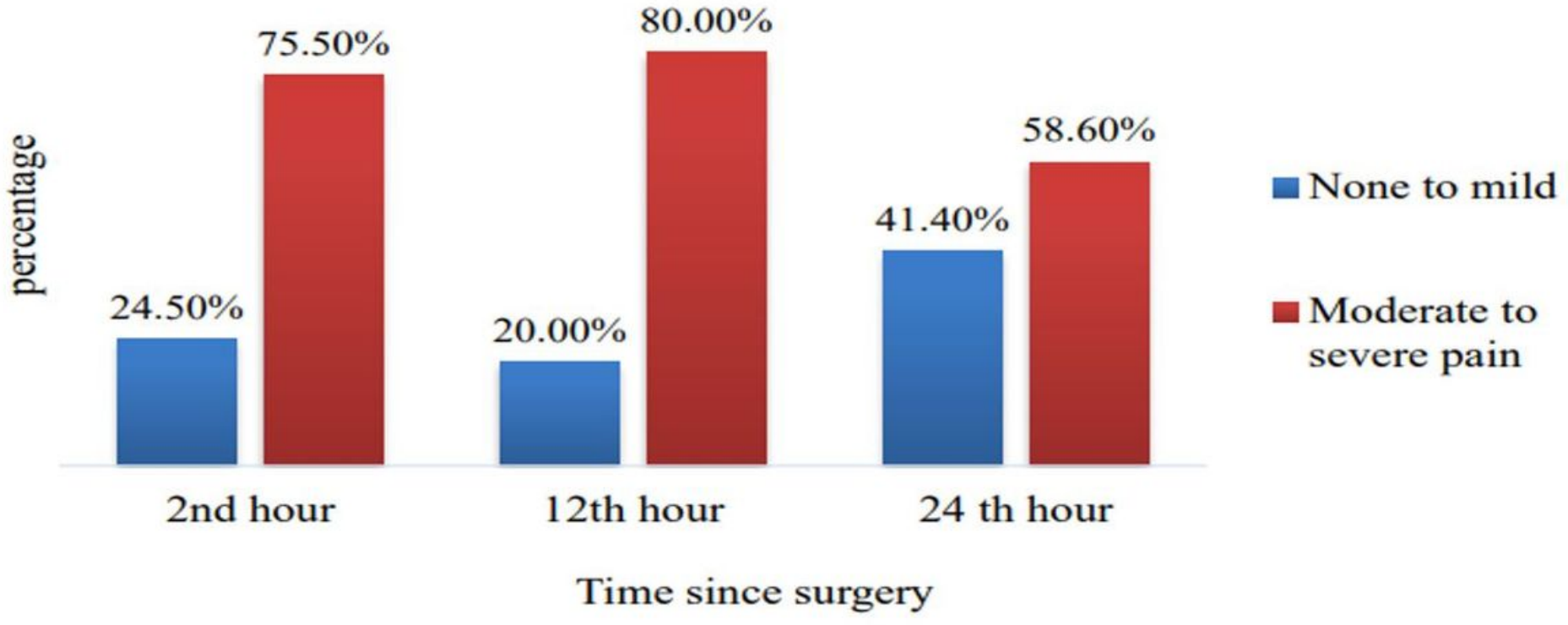

Figure 1

Pain after cesarean section at 2nd, 12th and 24th postoperative hours at University of Gondar Comprehensive Specialized Hospital, Northwest Ethiopia; 2019, ( $N=290)$

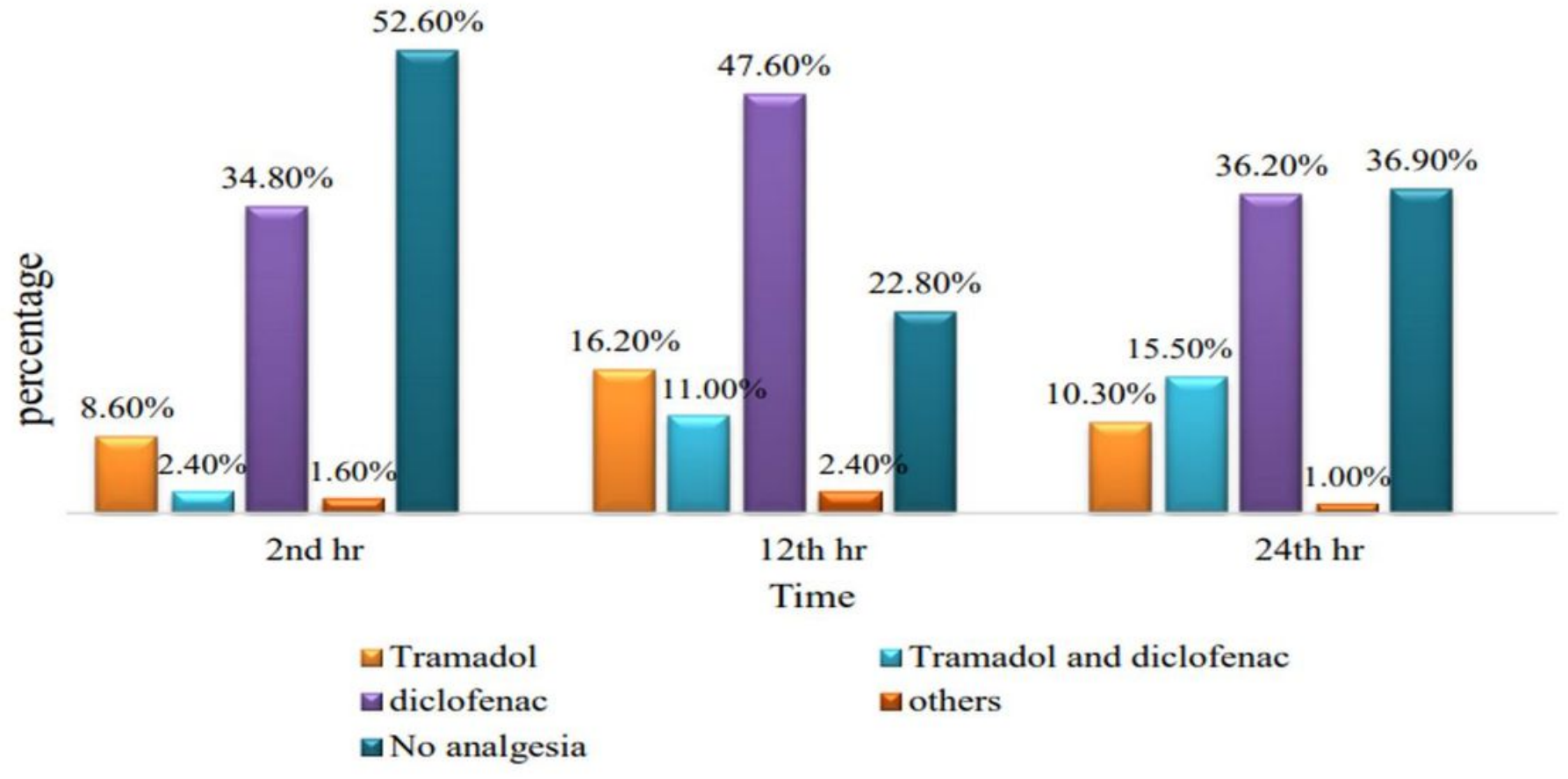

Figure 2

Systemic analgesics postoperatively given after cesarean section at the 2nd $\mathrm{hr}, 12 \mathrm{th} \mathrm{hr}$ and $24 \mathrm{th} \mathrm{hr}$ at University of Gondar Comprehensive Specialized Hospital, Northwest Ethiopia; 2019, ( $N=290)$. 


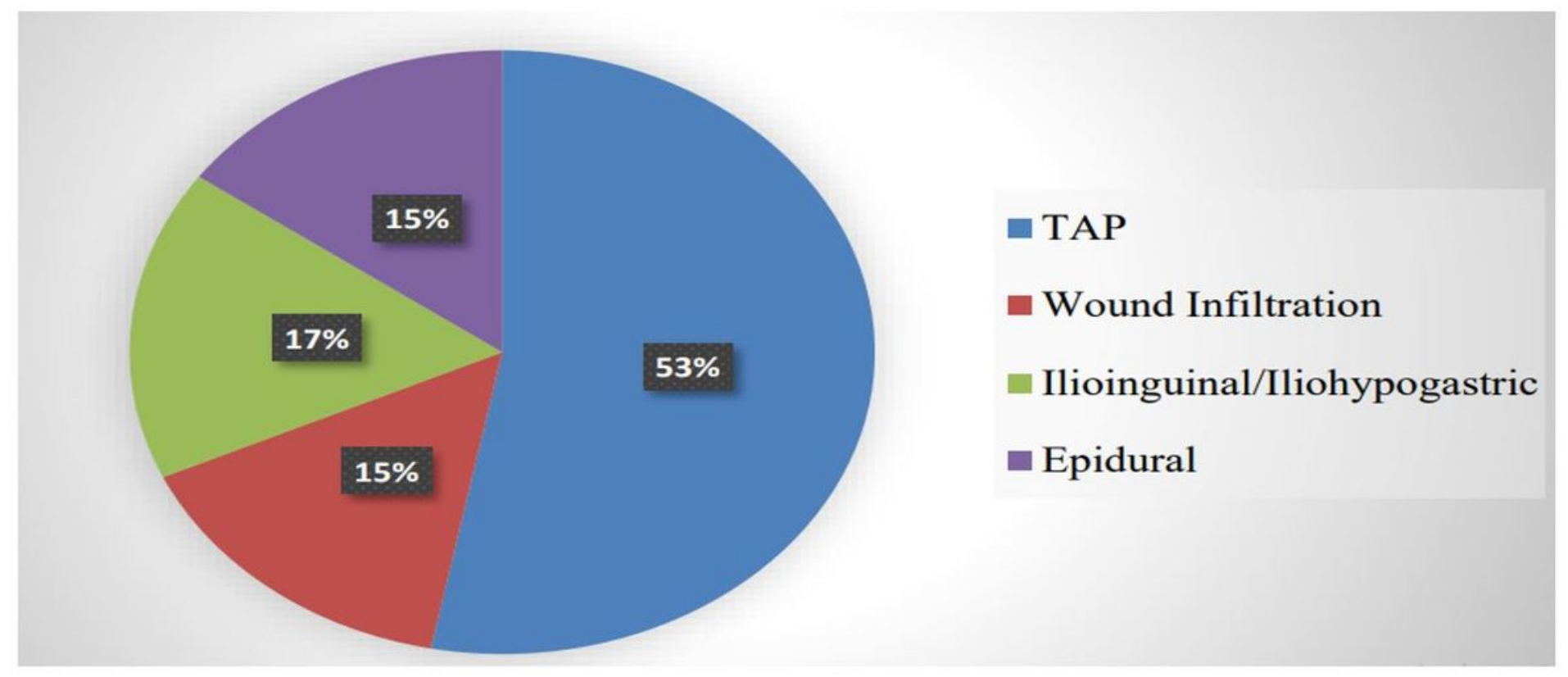

\section{Figure 3}

Regional analgesics provided for postoperative analgesia after cesarean section at University of Gondar Comprehensive Specialized Hospital, Northwest Ethiopia; 2019, ( $N=66)$. 